\title{
Comparative Analysis of Municipal Solid Waste Management in Kochi and Indore
}

\author{
B. Paul and D. Paul $\dagger$ \\ Department of Energy and Environment, Symbiosis Institute of International Business, Symbiosis International (Deemed \\ University), Pune-411057, Maharashtra, India \\ $†$ Corresponding author: Dipen Paul; dipen.paul@siib.ac.in
}

Nat. Env. \& Poll. Tech.

Website: www.neptjournal.com

Received: 24-09-2020

Revised: $15-10-2020$

Accepted: 08-12-2020

\section{Key Words:}

Municipal solid waste

Solid waste management

Waste segregation

\begin{abstract}
Conventionally, the general understanding of Municipal Solid Waste (MSW) management is collecting solid waste and its disposal through its developed channels or outside contracts. However, depending upon the situation and context, the definition of MSW varies between countries across the globe. For instance, in countries like Singapore and Japan, Municipal Solid Waste is defined as general waste. However, while categorizing the general waste, the industrial waste component is considered for Singapore and not for Japan. Similarly, different countries associate different definitions for MSW and it becomes a difficult challenge to suggest a single unified definition applicable for all countries. This paper aims to do a comparative analysis of Waste management in Tier-II cities of India, Kochi and Indore. Kochi is ranked $372^{\text {nd }}$ and the latter $1^{\text {st }}$ according to the latest Swachh Survekshan undertaken as part of the Swachh Bharat Abhiyan (Urban) by the Ministry of Housing and Urban Affairs. This paper highlights what the key elements missing out in the management of waste in Kochi from the reference perspective of Indore and identifying the measures Kochi needs to undertake to improve its ranking among the cleanest city in India are.
\end{abstract}

\section{INTRODUCTION}

In India, "Solid Wastes" are defined as solid or semi-solid domestic waste which is discarded after its primary use. The waste could be of any type depending upon the primary purpose of the product used. For example, sanitary waste from sanitary pads and napkins, commercial waste from food leftovers by restaurants, institutional waste, or industrial waste like concrete are all categorized as solid waste. Generally, these wastes are generated within the limits of local authorities and they are not categorized as a product or a by-product. The producer of the waste has no further use nor it is used for further production or consumption for it to be designated as a product. That is the reason why the generators decide to dispose of it. Waste generally includes materials generated during the life cycle of a product. Wastes are generated from the extraction of raw materials, processing of these raw materials into intermediates and final products, the consumption of final products, and other human activities excluding the residuals recycled or reused at the place of generation (MUD, GOI).

One of the core elements of a city's infrastructure is its solid waste management framework. As the city develops through increased urbanization, the demand for more human capital increases. These instances are a progressive part of any economic development and they have severe repercussions for the management of MSWs. More sophisticated management methods in MSW are required to reduce these repercussions which include activities that advocate socio-economic requirements (Sohkhlet \& Nagargoje 2020). A poor solid waste management system may create serious negative environmental impacts. Reports say that almost 1.6 billion tonnes of carbon dioxide equivalent were generated from solid waste management across the globe, representing about $5 \%$ of total greenhouse gas (GHG) emissions. The current solid waste management practices across the globe are poor and the amount of damage these practices caused is massive. Not only do they cause harm to the macro-level functioning of the world's ecosystem but also the micro-level functioning of the world's ecosystem. Clogged drainage systems are breeding grounds for bacteria, leading to several diseases. On a global scale, approximately $37 \%$ of the waste generated is disposed of in a landfill of which only $8 \%$ is disposed of in sanitary landfills, and the remaining 33\% is discarded in open fields and grounds in an unscientific manner. The global waste that is recovered through reuse, recycling, and composting is a mere 19\% (Sohkhlet \& Nagargoje 2020).

In India, the processes (collection, transportation, and disposal) involved in MSW management are very unscientific and chaotic. The dumping of wastes in and around the cities and towns has been increasing at an alarming rate without any proper control and landfills are found to be overflowing in 
major cities which is a real challenge for the country (Gupta et al. 1998). These landfills are very difficult to reclaim due to the unscientific manner in which the waste is dumped and poses serious environmental implications such as groundwater pollution and global warming. In lots of landfills, the burning of waste without the use of incinerators and other scientific measures is prevalent and is increasing leading to air pollution in terms of increased total suspended particles and particulate matter emissions, which is equivalent to vehicular emissions at times. When it comes to the recycling of solid waste, it has mainly remained an informal sector with the absence of proper waste segregation practices and awareness programs to promote and highlight the importance of waste management (Luthra 2020). Except for a few cities, the majority of the country is yet to implement new technologies in the management of MSW. Nevertheless, the sector holds a huge economic boost for the country which mainly is due to the thriving demand for waste material and recycled products that could help the nation accelerate towards sustainable progress (Dolla \& Laishram 2020).

In the context of this situation, we take two Indian cities, Kochi and Indore, which are both tier-II cities and part of the Smart Cities Mission undertaken by the Government of India. Since its inception, both the cities have been part of Swachh Survekshan and according to the results of the annual list of cleanest cities published in August 2020, Indore has emerged as India's cleanest city four years in a row, while Kochi was ranked 372, an improvement from 409 but below other regions from the state.

Dubbed as the "Queen of the Arabian Sea", Kochi is a metropolis located on the coast of Southern India in the state of Kerala bordering the Arabian Sea. Being gifted a beautiful natural harbor, it is one of the major port cities in India, falling near the international shipping lane. The city is often referred to as Ernakulam and is a part of the district of Ernakulam and the governing body of the city is the Kochi Municipal Corporation. The city is one of the most densely populated cities in southern India and as per the 2011 census, the population within the corporation limits stood at 677,381. Kochi holds the title of being the financial, commercial, and industrial capital of Kerala. Starting from being an important spice trading center from the $14^{\text {th }}$ century onwards, the city has progressed rapidly and has the highest GDP as well as the highest GDP per capita in the state.

Located in the state of Madhya Pradesh, the city of Indore is the largest and most populated state and is often dubbed as the educational hub of central India as it houses both the Indian Institute of Management and the Indian Institute of Technology. The city is governed by the Indore Municipal Corporation and the body is often considered among the best Municipal Corporations across the country. Indore had a census-estimated 2011 population of 1,994,397 (municipal corporation) and 2,170,295 (urban agglomeration). The city is the financial capital of Madhya Pradesh, being a commercial center for goods and services and having a GDP of \$14 billion as of 2011 .

\section{MATERIALS AND METHODS}

Solid waste management has always been an important social and environmental issue in a country like India and its prominence has been gaining traction nowadays. The country has witnessed a substantial increase in solid waste generation and its impact is very much visible in the urban areas of the country. Over the years since India opened its doors after 1991, the country has undergone a massive change with rapid urbanization fuelled by rapid population growth, who have been adapting and changing their lifestyles with changing standard of living, adopting new food habits, etc. (Malviya et al. 2002). All these trends have increased the stress on MSW management which was already in a stressful state. Due to a lack of financial resources, an unacceptable choice of technology, and public apathy towards municipal solid waste, the sector is struggling a lot. Due to these factors, the country has a huge challenge and pressure to address this social and environmental issue which mostly falls into the hands of the Municipal authorities (Aich \& Ghosh 2019).

Years ago, municipal waste was generally composed of biologically degradable matters since consumerism was low and the use of materials like plastic was very less. As a result, they did not create any serious problems for the communities as these were diverted for reuse or recycling through composting and later directly used as manure by the farming community (Ravi \& Vishnudas 2016). After the increase in the use of plastics and other non-biodegradable materials for production and packaging purposes, the accumulation of these non-biodegradable materials in the total quantity of municipal waste increased. With uncontrolled waste management practices employed, these materials found their way into the suburban agricultural community which became increasingly harmful to the farmers and cultivators. There are various aspects while dealing with this challenge and among them, there are two major aspects, the technology applied and the general social mindset of the people. The social mindset of the general public is an important aspect of the management of MSW and addressing this challenge forms the basis for controlled management of the waste. In India, the general notion among the public is, it is the responsibility of the government to dispose of whatever waste they are generating across all the sectors. This approach towards this aspect is very alarming and at the same time very pa- 
thetic. Only when society realizes that only they can manage this generated waste, the system becomes effective for the authorities and the environment. Municipal authorities must implement effective solid waste management which has to be executed ensuring that the adverse consequences on society are minimal. A centralized waste management system that is technologically driven has been developed and implemented in the developed industrial societies like Europe and North America (Ganesan 2017).

In India, Solid Waste Management (SWM) commensurates with the Solid Waste Management and Handling Rules, 2000 and 2016. The SWM rules 2000 voiced for a centralized waste management system where municipal governments were given the challenging task of playing a crucial role in the diversion of waste through the collection, processing, and final disposal of the solid. Due to various uncontrolled centralized waste management methodologies practiced by the municipal governments, the Solid Waste (Management and Handling) Rules, 2016 amendment was brought in as a deviation from its predecessor (SWM rules 2000) and the new rules prioritized the importance of source segregation and proper treatment of waste by improving the scope for recycling and reusing, thus focusing on the benefits that can be derived out of a circular economy. A study conducted by Rathore and Sarmah (2020) examined the economic, environmental, and social feasibility of circular economy in MSW management through a concept of converting collected organic MSW anaerobically into biogas and using that gas to generate electricity via a thermal power plant, thus reducing the overall dependency on coal-fired thermal power plants for power generation (Rathore \& Sarmah 2020). The proposed system was found out to reduce the economic, social, and environmental burden on MSW management and was successfully implemented in the city of Bilaspur, India. While studies based on community-based efforts for sustainable integrated waste management have been carried for megacities, its entire potential needs further introspection in terms of final execution depending upon the individual social commitments of those communities (Colon \& Fawcett 2006).
The state of Kerala witnessed a shift in its approach towards waste management from a centralized system to a decentralized system much before the amendment of SWM rules in 2016. The state produces approximately 3,410,243 MT of solid waste annually and the experience the state had with MSW has been important in changing the waste management rules of the country. A majority of the waste generated happens in the commercial capital of the state, Kochi and over the past years, the city has been struggling with its MSW.

The broad objective of this paper is to determine a technically and economically feasible solid waste management project for the city of Kochi which can be implemented in a phased manner by doing a comparative analysis with the city of Indore. The specific objectives of this paper:

- To compare the waste management in the Municipal Corporation of Kochi and Indore Municipal Corporation.

- Highlight the mechanism adopted by the two cities.

- Identify the challenges facing Kochi city and how the current measures implemented by Indore Municipal Corporation (IMC) can act as a solution for the city.

\section{RESULTS AND DISCUSSION}

Indore today generates over 1115 MT of garbage a day and all of the generated solid waste is collected at the source irrespective of being a residential or commercial establishment. The door-to-door waste collection services started in 2016 - in January as a pilot project. After a year, the city was collecting $100 \%$ waste through door-to-door services, and through its continuous efforts and collaborations with various residential and commercial units, they achieved $100 \%$ segregation of waste. None of this would have been possible without the efforts of the citizens of Indore who played a significant role in making the city neat and clean (Mokale 2019). Kochi has been growing at a rapid pace over the last decade and relentlessly pushing its borders cautioning the city planners. The number of high-rise apartments is among the highest in

Table 1: Projected population and total residential waste growth per day for Kochi and Indore.

\begin{tabular}{|c|c|c|c|c|c|c|}
\hline \multirow{2}{*}{ Year } & \multicolumn{3}{|c|}{ Kochi } & \multicolumn{3}{|c|}{ Indore } \\
\hline & Population & $\begin{array}{l}\text { Per capita waste } \\
\text { generated* }(\mathrm{kg})\end{array}$ & $\begin{array}{l}\text { Total waste } \\
\text { (Tons) }\end{array}$ & Population & $\begin{array}{l}\text { Per capita waste } \\
\text { generated* }(\mathrm{kg})\end{array}$ & $\begin{array}{l}\text { Total waste } \\
\text { (Tons) }\end{array}$ \\
\hline 2001 & 595575 & 0.518 & 308.51 & 1626297 & 0.321 & 522.04 \\
\hline 2011 & 601574 & 0.518 & 311.62 & 2104658 & 0.321 & 675.6 \\
\hline 2021 & 628645 & 0.518 & 325.64 & 2681831 & 0.321 & 860.87 \\
\hline 2031 & 656934 & 0.518 & 340.29 & 2912701 & 0.321 & 934.98 \\
\hline
\end{tabular}

*The per capita waste generated is assumed to be fixed concerning the $2012 \mathrm{CPCB}$ value. 
Table 2: Projected total increase per day in the share of different solid waste materials for Kochi and Indore in tonnes.

\begin{tabular}{|c|c|c|c|c|c|c|}
\hline \multirow{2}{*}{ Solid Waste Material* } & \multicolumn{3}{|c|}{ Kochi } & \multicolumn{3}{|c|}{ Indore } \\
\hline & 2011 & 2011 & 2021 & 2031 & 2021 & 2031 \\
\hline Paper & 2.52 & 5.47 & 6.97 & 7.57 & 2.64 & 2.76 \\
\hline Glass waste & 1.37 & 2.97 & 3.79 & 4.11 & 1.43 & 1.5 \\
\hline Metal waste & 1.99 & 4.32 & 5.51 & 5.98 & 2.08 & 2.18 \\
\hline Organic Waste & 136.96 & 296.93 & 378.35 & 410.92 & 143.12 & 149.56 \\
\hline Plastic waste & 1.93 & 4.19 & 5.34 & 5.8 & 2.02 & 2.11 \\
\hline Stones, ashes & 130.29 & 282.47 & 359.93 & 390.92 & 136.15 & 142.28 \\
\hline Miscellaneous & 36.55 & 79.25 & 100.98 & 109.67 & 38.2 & 39.92 \\
\hline
\end{tabular}

*The percentage share of different solid materials is assumed to be fixed concerning the 2012 CPCB value

Indian cities, adding more waste. Due to poor maintenance of roads and drainage system along with poor management of MSW by the Municipal Corporation, the city will have to endure many challenges, and coming out of these issues will be capital intensive if it attains a metropolitan status (Ravi \& Vishnudas 2018).

\section{Population}

While both the city's population is increasing based on the census studies, as per the analysis of the ecological footprint of waste generation in the residential areas of Kochi city, the city will be requiring an area equivalent to the current city size by 2050 if the present trend of MSW is followed upon.

\section{Waste Collection, Disposal and Treatment}

Table 2 represents the different types of solid waste generated and the approximate quantity of each type in 10 years. The values quantify the importance of segregation and the consequent smooth operation of the system.

\section{Kochi}

Approximately 47.5 residents of the city live in high-rise apartments while the remaining 52.5 percent have independent houses. The type of residence stems from the fact that most of the independent residence treat the waste generated at the premise itself, leaving the apartments to be completely dependent on the MSW services for waste treatment. The availability of land and the practice of unsustainable treatment measures lead to ineffective disposal of the waste. Therefore, the type of residence and the method of waste storage becomes crucial in implementing an efficient MSW.

The individual households mainly use three mechanisms for the treatment of waste:

- Household Treatment through composting or burning

- NGOs or Self-Help Group (Kudumbashree)

- Street Discard
The Kudumbashree and the Municipality have adopted door-to-door collection services for the households in Kochi covering both independent houses and high-rise apartments. Although the efficiency of Kudumbashree is applauded throughout the city, they only serve 15 wards of the total 71 wards present in Kochi City. The remaining wards are attended by the Municipal staff, whose unsatisfactory service delivery, households' unwillingness to pay the user charges associated with door-to-door waste collection, and the availability of land exacerbate the tendencies to adopt unsustainable practices such as street discard and burning.

Another major issue with the treatment of waste is the high proportion of non-segregated waste discarded on the streets. Even the municipal staff accept non-segregated waste from certain places. Those houses which chose to discard their waste on the streets usually use polythene bags to dispose of both biodegradable and non-biodegradable materials. The use of low-quality polyethylene bags affects the overall degradation process and efficient treatment. These wastes mix of non-segregated plastics, organic material, and plastics with non-recyclable quality eventually end up accumulating in the landfills (Sebastian, Kumar \& Alappat 2019). Plastics are a real threat to the environment as well as to the effective management of MSW.

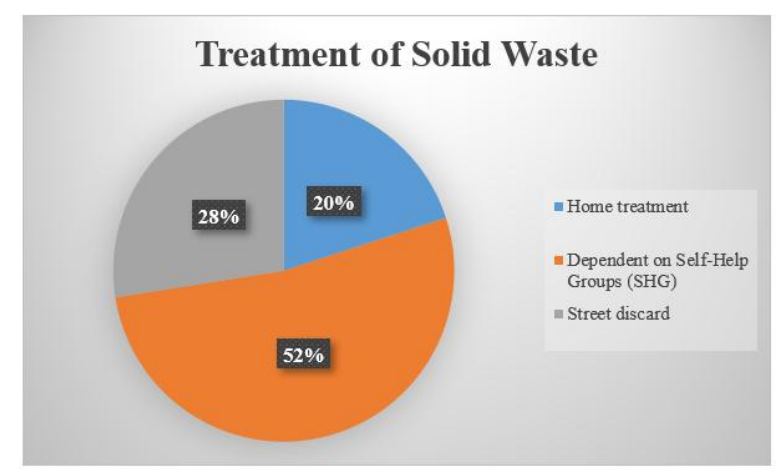

Fig. 1: Waste Treatment Methodology adopted by Kochi Households. 
The city collects a total of $40 \%$ of the waste produced and is transported to the treatment plant. Along with the Kudumbashree self-help workers and municipal staff members, Kochi has almost 250 resident associations that assist the officials in the door-to-door collection process. The city houses 21 sanitation circles which act as secondary collection points where the waste is collected after the primary collection which is done with the help of Hand Carts, Wheel Barrows and Tractor Trailers. From the secondary collection centers, the waste is transported to the final treatment site using a fleet of 107 vehicles which includes tractor-trailers, tippers, and other trucks.

The Brahmapuram solid waste treatment plant was constructed in 2008 as part of the plans of the Kochi Corporation to establish an efficient MSW management to address the increasing waste issue. It was built after acquiring 33.3 acres of wetland and rehabilitating the residents in Brahmapuram. The facility was designed for basically two treatment processes. Windrow composting for the treatment of biodegradable waste using trommels and a Refuse Derived Fuel pelletizer for the storage and treatment of nonbiodegradable waste. The plant was equipped with vehicles for leachate suction. The remaining waste materials were landfilled in the adjacent marshland.

The plant fell into negative criticism within a year of its operations. Due to negligence in the technical planning of the plant and poor operations, the structures of the facility developed cracks due to the broken floor and subsequent sinking. The columns tilted and the tie beams fell out of alignment. The authorities failed to factor in structural requirements for construction on a marshland which led to the subsequent breakage. The consequence of the broken floor and the subsequent breakage was that windrow composting was no longer viable in the plant due to retention of high moisture content resulting in the inefficient operations of mechanized composting and eventual accumulation in the landfill.

Currently, only $10 \%$ of the waste reaching the facility is being treated and the remaining $90 \%$ of solid waste entering the facility is landfilled. The excess waste accumulation in the landfill adjacent to river Kadamprayar has resulted in excessive leachate percolation and water pollution. To make matters more concerning is the fact that one of the biggest fish markets in Kochi, the Chambakkara market, lies on the downstream path of the river. Given the nature of the plant, the environmental impact of the Brahmapuram waste treatment plant is massive. Kochi as a city has a long way to go in implementing effective MSW management and timing has not been this crucial as it is now.

\section{Indore}

Indore is divided into 85 wards which fall under 19 zones.
Each ward has an average of 6000 households and numerous commercial establishments. The City specializes in collecting waste from all sources including residential, commercial, and industrial generators. Door-to-door collection service is implemented for household/apartment collection and bulk collection systems are used for semi bulk and bulk generators. With these systems in place, the city covers $100 \%$ of all the wards and ensures $100 \%$ collection from these wards.

The waste generators in Indore are classified as Domestic generators, Semi-Bulk Generators, and Bulk Generators based on the daily amount of waste generated. The generated waste is always segregated, and each classification segregates into different categories. Table 3 gives a detailed understanding of the classification of waste generators. The segregated waste generated by the domestic generators is collected by partitioned tippers known as Nigam trucks which have different chambers for different waste types. The chambers are fabricated in the ratio of 50:50, 60:40, and 85:15 depending upon the area and amount of the waste generated from the area. Each processing plant houses a computerized weighbridge which acts as the first point of interaction for the waste collection vehicles coming into the plant for offloading purposes. The vehicles are weighed upon entry and after offloading to determine the waste type. Upon completion, a receipt is generated and it is filed at the facility which contains all the information about the waste transported, the quantity, the type, source of waste, time, and vehicle details. All the dry wastes are transported to the Material Recovery Facilities (MRF) centers where they are offloaded for further segregation and processing. The wet waste from the GTS and Bulk generators are offloaded at the central composting plant for further processing. The domestic hazardous waste is offloaded at a separate facility after transferring from GTS in special biomedical vans. The domestic hazardous waste is transferred to the Common Biomedical Waste Facility (CBWTF) where it is incinerated.

Indore Municipal Corporation has to date constructed eight sophisticated ultra-modern Garbage Transfer stations to strengthen its secondary collection mechanism which overall brought in reduction to its cost of the secondary collection system and transportation system. Since the entire waste generated is processed, the corporation converted its

Table 3: Classification of waste generators in Indore.

\begin{tabular}{|lll|}
\hline Waste Generators & Amount/ Day & Segregation \\
\hline Domestic & $<25 \mathrm{Kg}$ & Wet, Dry, and Domestic \\
& & Hazardous \\
Semi-Bulk Generators & $25-100 \mathrm{Kg}$ & Wet and Dry \\
Bulk Generators & $>50 \mathrm{Kg}$ & Wet and Dry \\
\hline
\end{tabular}


Devguradia trenching site into a garden, demarcated it with a boundary wall, and planted 60,000 saplings. Once a dreadful place for the residents living close off, with constant fire and emission of foul smell, the achievement of Indore Municipal Corporation (IMC) is a benchmark for other Municipal Corporations to replicate and be a success story themselves.

The citizens of Indore were the true champions in making the entire system a grand success. Like any other Indian City, Indore too faced an existential crisis in dealing with its MSW. The steps adopted by the Information, Education, and Communication (IEC) played a crucial role in building the foundation for a Swachh Bharat Mission in Indore (Chauhan et al. 2020). IEC undertook the challenge of bringing about the behavior change required in the mindset of all the stakeholders, from citizens to the government authorities. They conducted a range of activities from cultural event promotions through street plays, wall paintings to mass communication strategy through content delivery via FM stations, social/ digital media campaigns, etc which brought out the much required behavioral change in all segments of the population, from residents to commercial establishment owners to industrial experts.

\section{CONCLUSION}

Indore is the cleanest city in India for four consequent years and that is not an easy milestone to achieve. Segregation is the base that has built a strong system in Indore which was brought in by creating a behavioural trait among the citizens through various awareness programs by the IEC. With the active participation of all the stakeholders and waste generators, Indore can process $100 \%$ of its waste. From being the most polluted city in Madhya Pradesh, the Madhya Pradesh Pollution Control Board (MPPCB) declared that the city's pollution levels have fallen by almost $50 \%$ to 80 micrograms per cubic meter which is very close to the safe limit set of 60 micrograms per cubic meter (Shrotriya \& Smout 2010). The standards of the air quality index are determined by the Central Pollution Control Board. From the grappling efforts of IMC in its early years to its current status, the city of Indore is a shining example for other big cities that are struggling with waste management woes.

The MSW management in Kochi is a ticking time bomb and if the present trends of management are to be followed, by 2050 the city will be requiring an area equivalent to its corporation size to treat the waste generated by the city households. The unsustainability dilemma in the minds of residents towards waste treatment and disposal has been pointed out especially through their behavioral aspects of street discards and burning. The authorities should focus on replicating the activities undertaken by the IMC and IEC on the importance of creating a behavioural trait towards sustainable waste management among all its residents and stakeholders. Implementing a better efficient decentralized waste management by contracting the Kudumbashree workers and covering all the wards for the collection of waste that is properly segregated is important for Kochi to address its waste woes. Since a huge proportion of the residents have undertaken the home treatment of solid waste, the Corporation authorities should assist the households in establishing an effective household treatment facility by constructing biogas plants and creating markets where the residents can avail monetary benefits from the manure produced.

Landfilling is not an option of Kochi city given its geographical nature and polity. The government and authorities must focus on creating technical and engineering innovations to reclaim the existing landfill. The Brahmapuram plant needs a complete revamp by redesigning the entire structure with strong foundations to optimize the windrow compositing and mechanized compositing which results in the reclamation of landfills. Waste to energy power plant should be constructed on a priority basis which reduces the burden on landfilling while making sure the environmental impacts of the entire waste management are minimum. Finally, the authorities and policymakers must set out the overall strategies for implementing an effective MSW management body for the city of Kochi by making stringent laws and corrective actions wherever necessary.

\section{REFERENCES}

Aich, A. and Ghosh, S. K. 2020. Framework for auditing of municipal solid waste management system in India. In Solid Waste Policies and Strategies: Issues, Challenges and Case Studies (pp. 85-99). Springer, Singapore.

Chauhan, J., Gautam, V. K. and Mishra, P. N. 2020. To study information, education, and communication (IEC) campaign as a tool to spread awareness in understanding the support of $3 \mathrm{R}$ concept for waste minimization in Indore City as the cleanest city of India. In Solid Waste Policies and Strategies: Issues, Challenges and Case Studies (pp. 7-25). Springer, Singapore.

Colon, M. and Fawcett, B. 2006. Community-based household waste management: Lessons learnt from EXNORA's 'zero waste management 'scheme in two South Indian cities. Habitat International, 30(4): 916-931.

Dolla, T. and Laishram, B. 2020. Factors affecting public-private partnership preference in Indian municipal waste sector. International Journal of Construction Management, 20(6): 567-584

Ganesan, P. 2017. Landfill sites, solid waste management and people's resistance: A study of two municipal corporations in Kerala. International Journal of Environmental Studies, 74(6): 958-978.

Gupta, S., Mohan, K., Prasad, R., Gupta, S. and Kansal, A. 1998. Solid waste management in India: Options and opportunities. Resources, Conservation and Recycling, 24(2): 137-154.

Luthra, A. 2020. Efficiency in waste collection markets: Changing relationships between firms, informal workers, and the state in urban India. Environment and Planning A: Economy and Space, 52(7): 1375-1394. 
M. Ramachandran, Vishal Fegade, N. Ganesh and Manoj Chaudhari, 2019. Municipal Waste Disposal Strategy by Fuzzy TOPSIS Method. International Journal of Engineering and Advanced Technology (IJEAT)

Malviya, R., Chaudhary, R. and Buddhi, D. 2002. Study on solid waste assessment and management-Indore city. Indian Journal of Environmental Protection, 22(8): 841-846.

Ministry of Urban Development (MUD), Government of India (GOI), MUNICIPAL Solid Waste Management, Part II: The Manual, 2016, Accessed on May 2020, http://swachhbharaturban.gov.in/writereaddata/ Manual.pdf

Mokale, P. Smart waste management under smart city mission: Its implementation and ground realities. International Journal of Innovative Technology and Exploring Engineering, 5(12): 3095-3103

Rathore, P. and Sarmah, S. P. 2020. Economic, environmental and social optimization of solid waste management in the context of circular economy. Computers \& Industrial Engineering, 145: 106510.

Ravi, A. and Vishnudas, S. 2018. Ecological footprint and waste footprint of Kochi City, India: A Combined Analysis. The Journal of Solid Waste Technology and Management, 44(4): 344-355.

Sebastian, R. M., Kumar, D. and Alappat, B. J. 2019. Easy estimation of mixed municipal solid waste characteristics from the component analysis. Journal of Environmental Engineering, 145(11): 1-11.

Shrotriya, V. and Smout, I. 2010. GHG emissions: an assessment at the municipal solid waste disposal site in Indore, India. International Journal of Environmental Technology and Management, 13(3-4): 362-371.

Sohkhlet, D. and Nagargoje, S. 2020. Municipal solid waste management: A comparative study between Sydney (Australia) and Pune (India). EDP Sciences, 170: 1-12. 